\title{
Rapid increase in summer surface ozone over the North China Plain dur- ing 2013-2019: a side effect of particulate matter reduction control?
}

Xiaodan Ma et al.

Correspondence to: Jianping Huang (jianping.huang@ noaa.gov) and Tianliang Zhao (tlzhao@ nuist.edu.cn)

The copyright of individual parts of the supplement might differ from the CC BY 4.0 License. 


\section{List of Supplemental Figures}

Fig. S1 Spatial distributions of a) $\mathrm{NO}_{\mathrm{x}}$ and b) VOCs emissions from Multi-resolution Emission Inventory in China used in this study. . . . . . . . . . . 3

Fig. S2 A comparison of spatial distributions of monthly mean of $\mathrm{NO}_{2}\left(\mu \mathrm{g} \mathrm{m}^{-3}\right)$ monitored by China National Environmental Monitoring Center between (a) 2013 and (b) 2019 in eastern China (NCP indicated by the

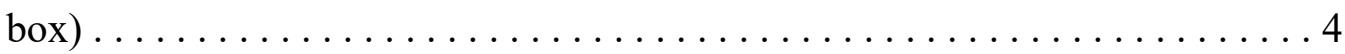

Fig. S3 Long-term changes in monthly mean of observed $\mathrm{Ox}\left(\mathrm{NO}_{2}+\mathrm{O}_{3}\right)$ averaged over the North China Plain (a) and urban areas Beijing in daytime (redline) and nighttime (blackline) in June over the period of $2013-2019 \ldots \ldots \ldots \ldots \ldots$

Fig. S4 A comparison of monthly means of (a) the maximum daily 8-h average (MDA8) $\mathrm{O}_{3}(\mathrm{ppb})$, (b) particulate matters with aerodynamic diameter of 2.5 micrometers $\left(\mathrm{PM}_{2.5}\right)\left(\mu g \mathrm{~m}^{3}\right),(\mathrm{c})$ aerosol optical depth (AOD), (d) Tropospheric Column of $\mathrm{NO}_{2}\left(\mathrm{TCNO}_{2}\right)\left(10^{15} \mathrm{~cm}^{-2}\right)$, (e) daily max temperature at $2 \mathrm{~m}\left(\mathrm{~T}_{2 \mathrm{max}}\right)\left({ }^{\circ} \mathrm{C}\right),(\mathrm{f})$ short-wave radiation $\left(\mathrm{W} \mathrm{m}^{-2}\right)$, and $(\mathrm{g})$ planetary boundary layer height $(\mathrm{PBLH})$ $(m)$ in North China Plain over the period of $2013-2019 \ldots \ldots \ldots \ldots 6$

Fig. S5 Average diurnal profiles of (a) $\mathrm{O}_{3}$, (b) $\mathrm{NO}_{2}$, (c) $\mathrm{PM}_{2.5}$ in June of 2013 (black.

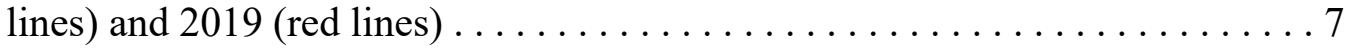

Fig. S6 Long-term changes in monthly mean of observed $\mathrm{NO}_{2}$ averaged over the North. China Plain in June over the period of $2013-2019 \ldots \ldots \ldots \ldots \ldots$ 

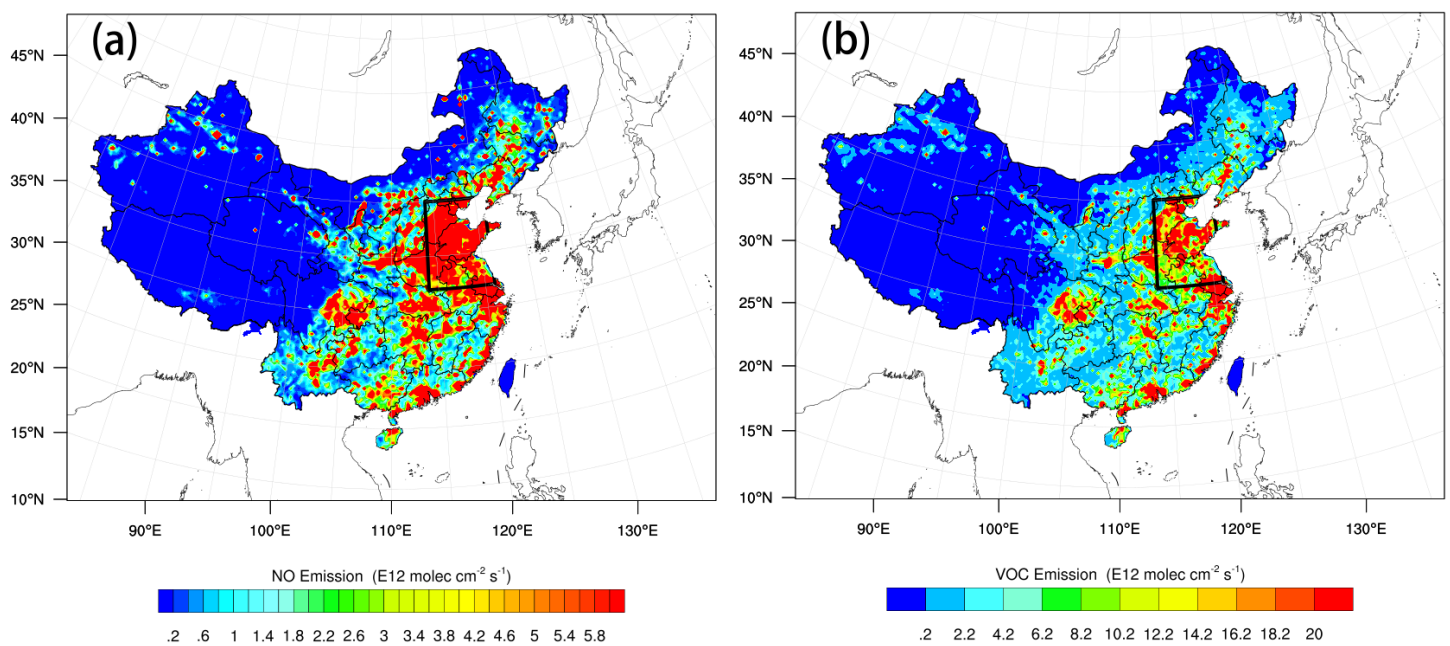

Figure S1. Spatial distributions of a) $\mathrm{NO}_{\mathrm{x}}$ and b) VOCs emissions from Multi-resolution Emission Inventory in June for year-2013 in China used in this study (http://www.meicmodel.org/). 

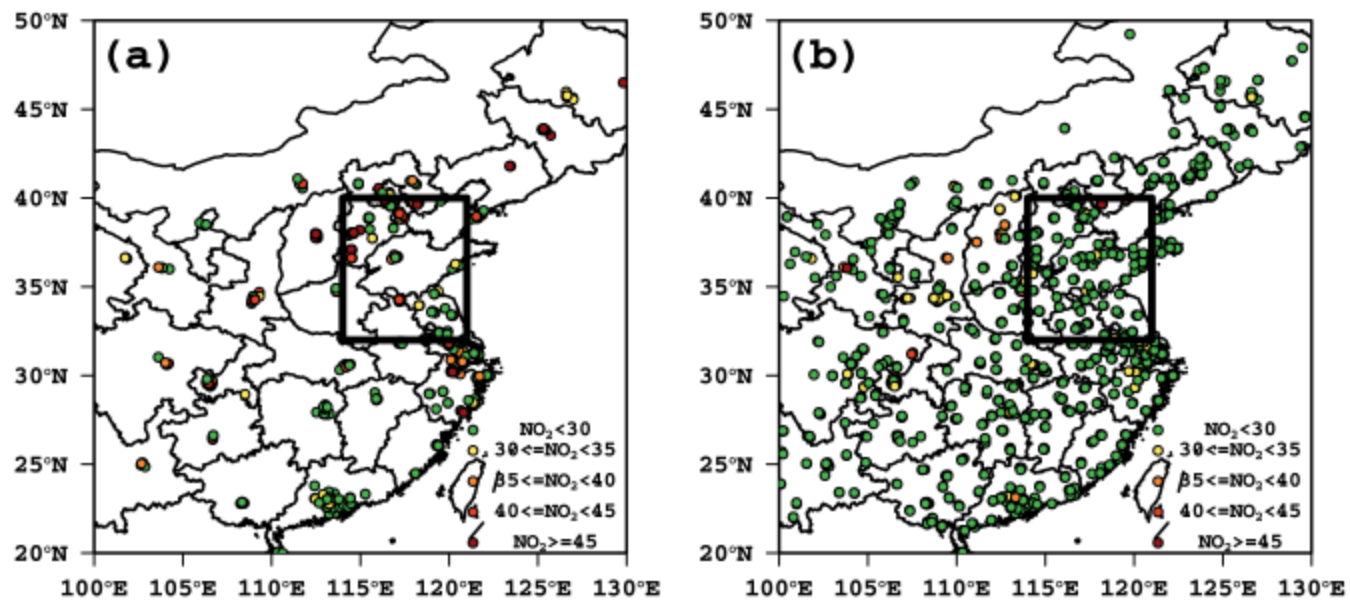

Figure S2. A comparison of spatial distributions of monthly mean of $\mathrm{NO}_{2}\left(\mu \mathrm{g} \mathrm{m} \mathrm{m}^{-3}\right)$ monitored by China National

Environmental Monitoring Center between (a) 2013 and (b) 2019 in eastern China (NCP indicated by the box). 

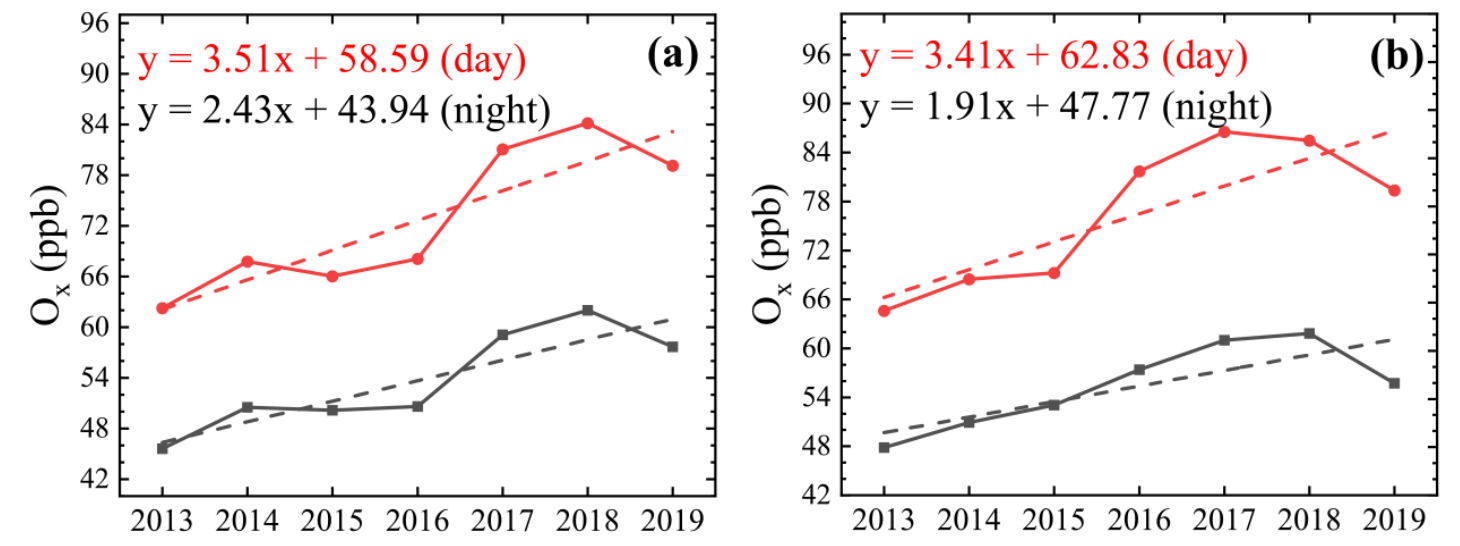

Figure S3. Long-term changes in monthly mean of observed $\mathrm{Ox}\left(\mathrm{NO}_{2}+\mathrm{O}_{3}\right)$ averaged over the North China Plain (a) and urban areas Beijing in daytime (redline) and nighttime (blackline) in June over the period of 2013-2019. 

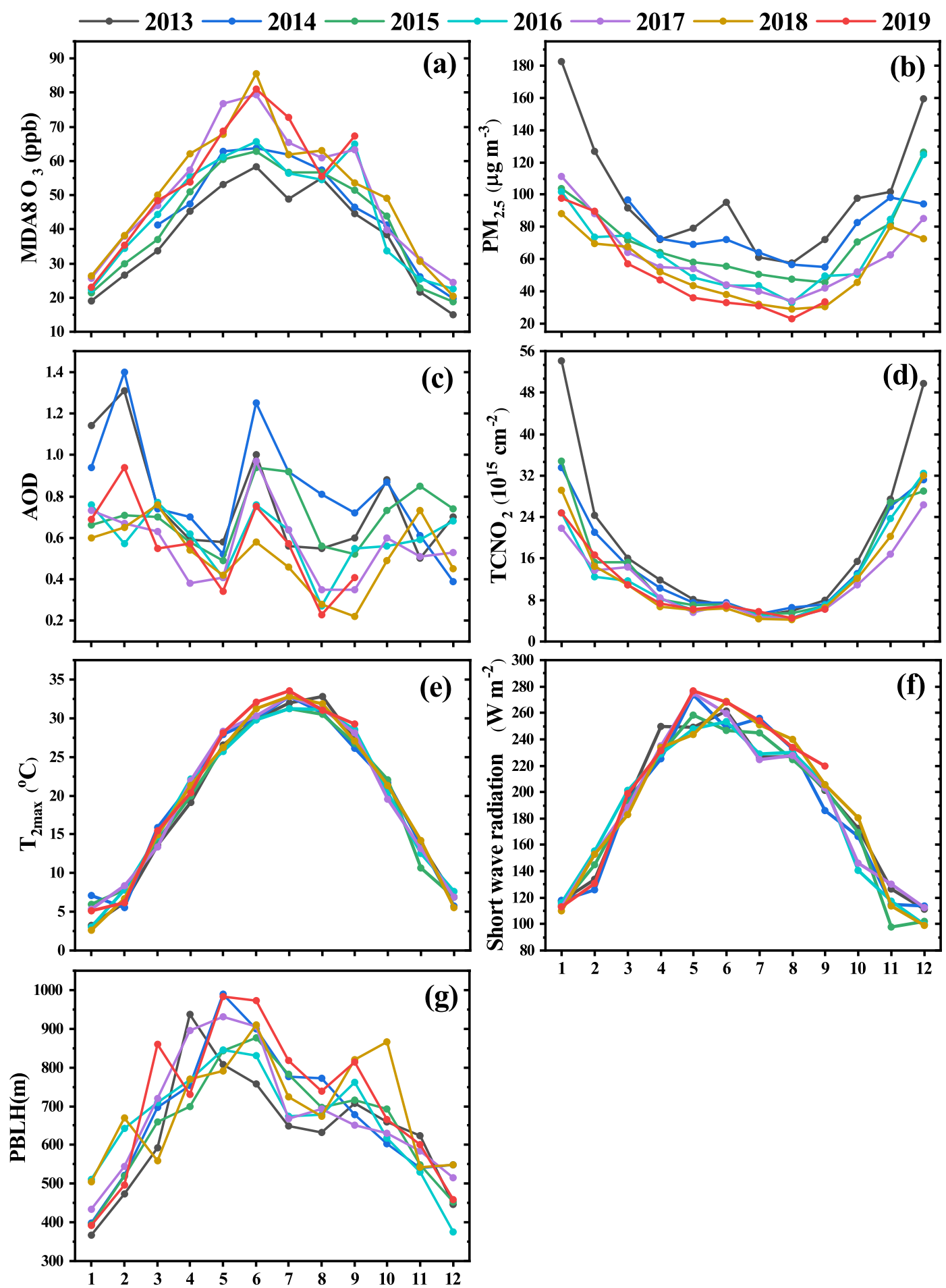

Figure S4. A comparison of monthly means of (a) the maximum daily 8-h average (MDA8) $\mathrm{O}_{3}$ (ppb), (b) particulate matters with aerodynamic diameter of 2.5 micrometers $\left(\mathrm{PM}_{2.5}\right)\left(\mu g \mathrm{~m}^{3}\right)$, (c) aerosol optical depth (AOD), (d) Tropospheric Column of $\mathrm{NO}_{2}\left(\mathrm{TCNO}_{2}\right)\left(10^{15} \mathrm{~cm}^{-2}\right)$, (e) daily max temperature at $2 \mathrm{~m}\left(\mathrm{~T}_{2 \max }\right)\left({ }^{\circ} \mathrm{C}\right)$, (f) short-wave radiation $\left(\mathrm{W} \mathrm{m}^{-2}\right)$, and $(\mathrm{g})$ planetary boundary layer height $(\mathrm{PBLH})(\mathrm{m})$ in North China Plain over the period of 2013-2019. 

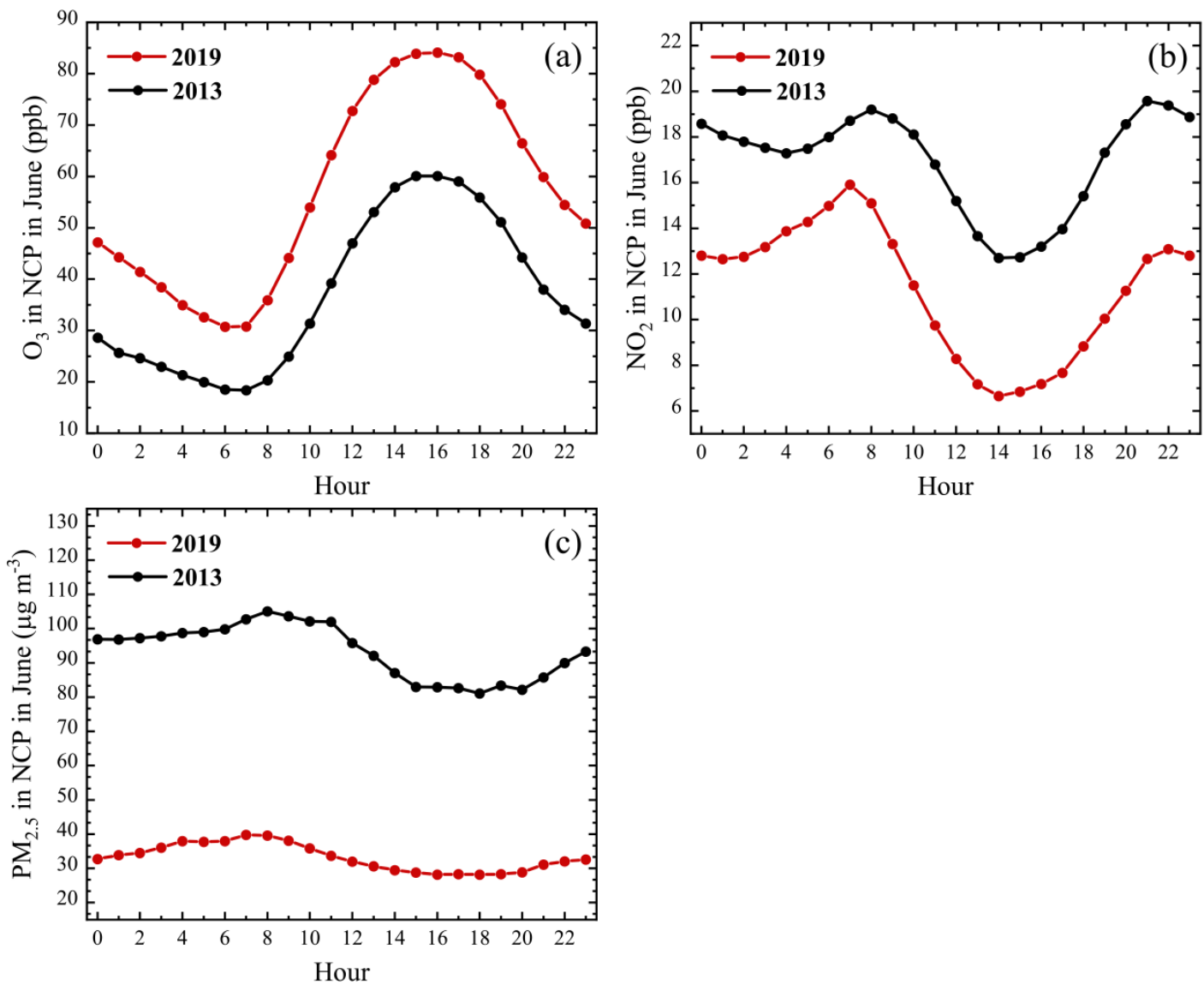

Figure S5. Average diurnal profiles of (a) $\mathrm{O}_{3}$, (b) $\mathrm{NO}_{2}$, (c) $\mathrm{PM}_{2.5}$ in June of 2013 (black lines) and 2019 (red lines). 


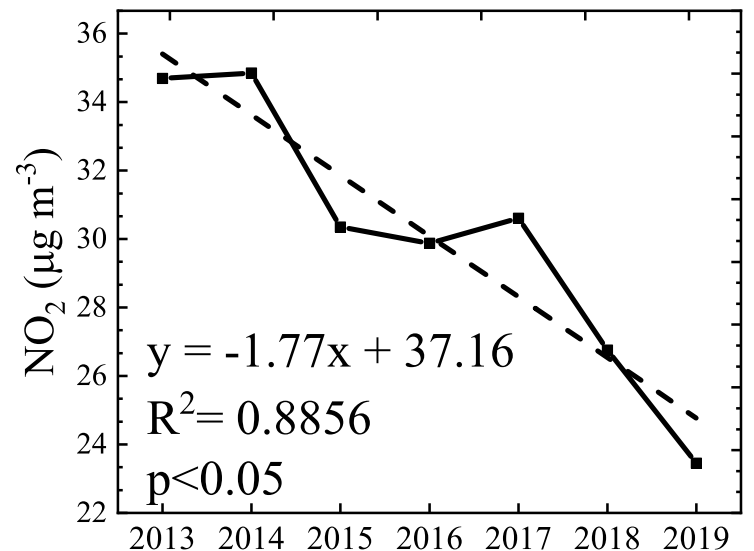

Figure S6. Long-term changes in monthly mean of observed surface $\mathrm{NO}_{2}$ averaged over the North China Plain in June over the period of 2013-2019. 